\title{
O declínio do Brasil-nação
}

\author{
OCTAVIO IANNI
}

$\mathrm{E}$ STA É A IRONIA da história: o Brasil nasce no século XVI como província do colonialismo e ingressa no século XXI como província do globalismo. Depois de uma longa e errática história, através do mercantilismo, colonialismo e imperialismo, ingressa no globalismo como modesto subsistema da economia global. A despeito dos surtos de nacionalismo e das realizações propriamente nacionais, como ocorre principalmente na época do populismo, isto é, do projeto e realizações do capitalismo nacional, ingressa no século XXI como simples província do capitalismo global; revelando-se um caso de dependência perfeita.

Mas vamos por partes. O assunto tem grande importância prática e teórica. Vale a pena refletir criticamente sobre o que está ocorrendo no Brasil, quando se verifica um novo surto de globalização do capitalismo.

O que caracteriza a encruzilhada em que se encontra o Brasil na transição do século XX ao XXI é o abandono e o desmonte do projeto nacional, com as suas implicações político-econômicas e sócio-culturais, e a implantação de um projeto de capitalismo transnacional, com as suas implicações políticoeconômicas e sócio-culturais. Está em curso a transiç̧ão de uma nação em pro-

o abandono

e o desmonte do projeto nacional ... víncia, com a transformação do aparelho estatal em aparelho administrativo de uma província do capitalismo global. Mais uma vez, verifica-se que o Estado pode transformar-se em aparelho administrativo das classes dominantes; neste caso classes dominantes em escala mundial, para as quais os governantes nacionais se revelam simples funcionários.

A encruzilhada aparece como conjuntura critica, coleção de impasses, eleição de perspectivas. Também aparece como uma conjuntura de inquietações e interrogações, antes do que perspectivas e convicções, no que se refere às condições e aos horizontes dos diferentes setores sociais. Aí, indivíduos e coletividades, classes e grupos sociais, partidos políticos e movimentos sociais, sindicatos e correntes de opinião pública, situam-se, movem-se, desesperam-se ou formulam perspectivas. É como se houvesse uma estranha coincidência: a encruzilhada em que se encontra o Brasil parece ser a mesma em que se encontram outros países, todos inseridos na crise que 
assinala a transição do século XX ao século XXI. Na verdade, essa é uma ruptura histórica de amplas proporções, práticas e teóricas, na qual se encontram os povos e as nações, em escala mundial; todos metidos em um novo surto de globalização do capitalismo.

É possível demonstrar que o modelo de capitalismo transnacional instalou-se por etapas. Nos anos 1964-85 a ditadura militar, consciente ou inconscientemente, destroçou lideranças e organizações políticas comprometidas com o modelo de capitalismo nacional. Nos anos 1985-94 os diversos governos adotaram medidas econômico-financeiras de cunho neoliberal. E desde 1994 o governo empenha-se totalmente na concretização das instituições e diretrizes econômico-financeiras destinadas a completar a instalação do projeto de capitalismo transnacionalizado, segundo as diretrizes teóricas, práticas e ideológicas do neoliberalismo.

Esta é a questão central, se queremos esclarecer quais são os nexos que constituem a encruzilhada na qual o Brasil se encontra na transição do século XX ao XXI: desmonta-se o projeto de capitalismo nacional e instalase o projeto de capitalismo transnacional. Esse o significado principal da "Reforma do Estado", compreendendo a criação do "Estado mínimo", isto é, desregulação, privatização, abertura de mercados, favorecimento de fusões e aquisições de empresas nacionais por transnacionais. Muito simbolicamente, o BNDES, que se havia criado de forma a servir à política de industrialização substitutiva de importações, nos moldes do projeto de capitalismo nacional, é reorientado de forma a favorecer a transnacionalização, ou seja, ao desmonte do projeto de capitalismo nacional. Simultaneamente, intensifica-se a privatização dos sistemas de ensino e de saúde, ao mesmo tempo em que se redefinem as relações de trabalho e as condições de funcionamento da previdência, de maneira a favorecer a transformação dessas esferas da "questão social" em espaços de aplicação lucrativa do capital privado, no qual predominam as empresas, corporações e conglomerados transnacionais.

Vale a pena examinar alguns aspectos práticos e teóricos do modelo de capitalismo transnacionalizado, também denominado eufemisticamente de "mercado emergente" ou de "industrialização orientada para a exportação". Esse modelo tem sido apresentado em termos de "Reforma do Estado", destinada a reinserir ou inserir mais amplamente o Brasil na economia globalizada.

A reforma do Estado, nos termos em que está sendo realizada, seguindo fielmente as diretrizes do Consenso de Washington, isto é, do neoliberalismo, implica uma redefinição drástica das relações entre o Estado e a 
Sociedade, e não apenas com a Economia; mesmo porque ambas se constituem simultânea e reciprocamente com os seus ingredientes políticos e culturais. Este é o processo que se acha em curso: o Estado está sendo dissociado da Sociedade; suas relações estão sendo redefinidas; altera-se e rompe-se o metabolismo que se havia desenvolvido entre a Sociedade e o Estado na vigência do projeto de capitalismo nacional.

Desde que se intensificam e generalizam as implicações institucionais, econômicas, sociais, políticas e culturais da Reforma do Estado, ou seja, do desmonte do projeto de capitalismo nacional, com a crescente abertura da economia à transnacionalização, logo se acentuam processos tais como os seguintes.

Primeiro, dissociação crescente entre as linhas principais de atuação do Estado e as tendências predominantes na Sociedade, reconhecendo-se que esta pode ser vista como um complexo de classes e grupos sociais dominantes e subalternos; lembrando-se que os subalternos são a grande maioria do povo.

Cria-se, desenvolve-se e aprofunda-se uma singular dissociação entre o Estado e a Sociedade. Em outras palavras, as diretrizes econômico-financeiras, políticas e culturais prevalecentes no âmbito do Estado são cada vez mais evidentemente alheias às necessidades econômico-financeiras, políticas e culturais da maior parte da Sociedade civil. O povo, enquanto um conjunto de classes e grupos sociais subalternos, é esquecido pelos dirigentes, já que estes estão empenhados em "modernizar", "racionalizar" ou "dinamizar" as instituições nacionais de forma a intensificar a "inserção" da "emergente" economia na dinâmica do capitalismo mundial. Os governantes, em conformidade com as diretrizes e injunções das estruturas mundiais de poder, isto é, corporações transnacionais, Fundo Monetário Internacional (FMI), Banco Mundial (BIRD) e Organização Mundial do Comércio (OMC), entre outras, empenham-se em "reformar" o Estado e o conjunto das instituições nacionais, com o objetivo de acentuar a acomodação do "mercado emergente" com o mercado mundial.

Uma das conseqüências mais imediatas, evidentes e generalizadas do desenvolvimento intensivo e extensivo do capitalismo global é o crescente enfraquecimento ou mesmo evidente dissolução do tecido social. Formas de sociabilidade que pareciam estabelecidas, entram em crise, perdem vigência, tornam-se anacrônicas ou mesmo dissolvem-se. Em lugar do partido político, do sindicato, do movimento social e da corrente de opinião pública, coloca-se a mídia como um insólito, mas presente, eficaz e ubíquo "príncipe eletrônico". Muito do que os indivíduos e as coletividades pensam, 
sentem, imaginam ou fazem relaciona-se direta e indiretamente com a poderosa e ubíqua indústria cultural desenvolvida em âmbito local, nacional, regional e mundial, indústria essa organizada em poderosas empresas, corporações e conglomerados eletrônicos. Em lugar do espaço público, enquanto lugar privilegiado da política, colocam-se os programas de auditório, os eventos da cultura mundial de massa, as competições, os shows, tudo isso crescentemente transnacional.

Em muitos casos, os shopping centers expressam, simbolizam e revelam-se sucedâneos de espaços públicos. Nesses casos, os indivíduos e as coletividades são induzidos a comportar-se de tal modo que o consumismo aparece como uma figuração de cidadania. São muitas as evidências de que as formas de sociabilidade que se conheciam estão sendo drástica e generalizadamente modificadas. Está em curso a expansão das formas de sociabilidade determinadas pelo mercado, o consumismo, a organização sistêmica das estruturas mundiais de poder, a dinâmica empresarial, a lógica do capital, a razão instrumental.

Segundo, a Sociedade civil transforma-se em uma nebulosa em busca de redefinição, já que os partidos políticos, sindicatos, movimentos sociais,

\section{a Sociedade civil} está desafiada a rearticular-se sob outras e novas formas ... correntes de opinião pública, mídia e igrejas que articulam a Sociedade civil são desafiados a dialogar com um governo e aparelho estatal comprometidos apenas ou principalmente com matéria econômico-financeira; sem esquecer o monopólio da violência, por suas organizações policiais, militares e de informação, em geral alheias e adversas aos sentimentos e aos interesses das classes e grupos sociais subalternos. Isto significa que a Sociedade civil está desafiada a rearticular-se sob outras e novas formas, criando o recriando instituições, organizações e reivindicações em condições de expressar diferentes possibilidades de entendimento e emancipação.

É óbvio que amplos setores da Sociedade civil, precisamente os subalternos, ou seja, os que não têm acesso às estruturas "nacionais" e transnacionais de poder, esses setores são levados a um verdadeiro choque: desnorteiam-se e desagregam-se. É como se a Sociedade civil em pouco tempo se tornasse acéfala. Em lugar do metabolismo mais ou menos efetivo que se desenvolvia com o projeto nacional, agora instala-se a dissociação, ou desencontro, devido às diretrizes assumidas pelos governantes, diretrizes essas alheias ou mesmo em contraposição às inquietações e reivindicações da Sociedade civil. 
Esse é o clima em que se cria uma situação particularmente problemática para os setores sociais subalternos: precisam reestruturar-se em novos moldes, desenvolver uma nova consciência das suas condições e perspectivas, recriar meios e modos de atuar politicamente; sem saber se ainda lhes restam possibilidades de construir hegemonias alternativas. Desde que o Estado se torna principalmente um aparelho administrativo das classes e grupos, ou blocos de poder, dominantes em escala mundial; desde que as instituições nacionais são reformadas em conformidade com as estruturas mundiais de poder; desde que classes e grupos sociais dominantes já não revelam quaisquer compromissos com a nação, a Sociedade civil, o povo; desde tudo isso, quais poderiam ser as condições de construção de hegemonias alternativas?

Terceiro, dadas as prioridades estabelecidas com as diretrizes neoliberais, ditadas principalmente por FMI, BIRD, OMC e as corporações transnacionais, o Estado transforma-se em um aparelho administrativo alheio à Sociedade, alheio às tendências predominantes no âmbito das classes e grupos sociais que compõem a maioria do povo. Essa é a realidade: o Estado transforma-se em mero aparelho administrativo dos blocos de poder transnacionais. Esse o contexto em que as "elites" governantes aparecem como estranhas e simplesmente administrativas, impondo-se à grande maioria do povo; uma coleção de conquistadores e colonizadores, em geral servidos por intelectuais, cientistas sociais e outros profissionais com todas as características de "brazilianistas nativos".

Quarto, esta é uma conseqüência mais ou menos evidente: a economia brasileira transforma-se em mera provincia do capitalismo mundial. Todas as principais decisões que se adotam em âmbito governamental, com sérias implicações em âmbito da vida cotidiana de indivíduos e coletividades, são ditadas principalmente pelas exigências da transnacionalização. Subsistem a sociedade nacional e o Estado, a cultura e a língua, a história e as tradições, os santos e os heróis, os monumentos e as ruínas, mas modificados, deslocados, muitas vezes folclorizados ou emblemas de nostalgias. A parte principal do solo do Estado-nação transnacionaliza-se, torna-se pasto das corporações transnacionais.

Quinto, ainda, este é um fato novo e fundamental, com diversas e profundas implicações nas relações Estado e Sociedade civil: o novo ciclo de globalização do capitalismo solapa as bases econômicas e políticas da soberania e atinge inclusive as suas bases sociais e culturais. A soberania, como instituto jurídico-político nuclear do Estado-nação perde vigência, ou transforma-se em uma ficção da retórica política e dos ordenamentos jurídicos, mas sem condições de vigência efetiva na definição de algum projeto nacio- 
nal, na formulação de diretrizes político-econômicas e sócio-culturais relativas ao nacional; no estabelecimento das condições e possibilidades de tradução das inquietações e reivindicações de setores sociais subalternos em compromissos e diretrizes de governo, das políticas que se adotam no âmbito do poder estatal. É tal a envergadura da transformação qualitativa do Estado-nação, devido às injunções do globalismo, que os governantes já não conseguem mais se apresentar como estadistas; parecem muito mais funcionários dóceis traduzindo para a língua "nativa" o que se dita no idioma das corporações transnacionais e das organizações multilaterais; sendo que alguns parecem figurações de um teatro mundial de títeres.

Diante dessa nova e profunda crise de hegemonia, com suas implicações em diferentes setores da sociedade nacional e comprometendo pela base o Estado-nação, criam-se vários problemas fundamentais, por suas implicações práticas e teóricas.

A sociedade nacional se vê impossibilitada de por em prática qualquer projeto nacional que dependa da vigência efetiva do princípio jurídico-político da soberania nacional. Ao adotar o projeto de capitalismo transnacional, desenvolve-se não só a transnacionalização mas também a alienação de centros decisórios. A despeito da vigência dos aparelhos estatais, dos partidos políticos e sindicatos, bem como da preservação de signos, símbolos e emblemas nacionais, o Estado-nação se torna uma entidade de outro tipo, sem algumas das suas bases econômicas e jurídico-políticas, o que contamina toda a sociedade, ainda que em diferentes gradações; torna-se um aparelho administrativo obrigado a acomodar as condições e exigências da transnacionalização crescente da economia, compreendendo a ampla "liberação" das forças produtivas, esquecendo as exigências de setores sociais subalternos.

Esta é uma lição importante, quando se trata de entender como se realiza a transição do projeto de capitalismo nacional para o projeto de província do capitalismo global: As "elites" dominantes, compreendendo empresariais, militares, intelectuais e do alto clero revelam-se com escasso ou nulo compromisso com a nação, o povo, a sociedade. Organizam-se e movem-se como "elites" enraizadas no poder político-econômico conferido pelos monopólios, trustes, cartéis, corporações e conglomerados transnacionais; algo que vem do imperialismo e impregna amplamente o globalismo. Em sua maioria, os membros dessas "elites", isto é, classes e grupos sociais dominantes, ou blocos de poder, organizam-se e comportam-se como conquistadores, colonizadores, desfrutadores. Estão inclinados a associar-se com os monopólios, trustes, cartéis, corporações, conglomerados; e inclinados a considerar o país, a sociedade nacional e o povo como território de negócios, pastagem de lucro, ganhos. 
Tanto é assim, que definem as fusões e as aquisições de empresas nacionais promovidas pelas transnacionais como "modernização", "inserção no mercado mundial", "entrada no primeiro mundo". Esquecem o agravamento das desigualdades sociais, o desemprego estrutural, a pauperização, a lumpenização. Esquecem a evidente e acentuada dis-

\section{esquecem o agravamento} das desigualdades sociais, o desemprego estrutural ... solução do tecido social, a perda de perspectivas por parte de grandes setores do povo. Parecem utilizar a generalização da violência e do medo como técnicas de criminalização da Sociedade civil, o que ajuda a manter e fortalecer os aparelhos de repressão e de intimidação generalizada de amplos setores sociais; precisamente dos setores empenhados em construir formas alternativas de hegemonia.

Daí o difícil e problemático retorno da questão nacional, o desafio de recriar a Sociedade civil e o Estado, ou levar a Sociedade civil a "educar duramente o Estado". Trata-se de reavaliar ampla e radicalmente as condições sob as quais se realiza a transição do modelo de capitalismo nacional para o de capitalismo transnacionalizado, reconhecendo-se que o "ciclo" de globalização do capitalismo em curso nesta época cria outras, novas e difíceis condições para a organização e dinâmica do Estado-nação, compreendendo o contraponto nacionalismo e regionalismo, no âmbito do globalismo; compreendendo alianças e ações de setores, grupos e classes subalternos em âmbito transnacional.

Em se tratando de encruzilhada, tendo-se em conta o nacional e o mundial, ou nacionalismo e globalismo, cabe reconhecer que os dilemas com os quais se defronta a sociedade brasileira são semelhantes aos que enfrentam, já enfrentaram ou irão enfrentar outros países. Sob vários aspectos, pode-se afirmar que o que está ocorrendo no Brasil é não só semelhante ao que ocorre em outros, mas exemplar; uma espécie de experimento dos dilemas que se criam com o novo ciclo de globalização do capitalismo em curso na transição do século XX ao XXI; um experimento exemplar de dependência perfeita.

Acontece que os processos e as estruturas político-econômicos mundiais, compreendendo as corporações transnacionais e o FMI, o BIRD e a OMC, entre outras organizações e estruturas de poder, com freqüência atropelam a capacidade decisória de governos e setores sociais nacionais; atropelam soberanias nacionais; criam sérios obstáculos à construção de hegemonias alternativas; satanizam movimentos sociais e correntes de opinião pública com os quais se propõem alternativas destinadas a reduzir e eliminar os efeitos perversos da globalização do capitalismo. 
Diante dessa situação, realmente nova e difícil, cabe aos amplos setores sociais nacionais mais prejudicados pela globalização pelo alto reconhecer que precisam mobilizar-se também em escala global, desde baixo, compreendendo as classes e os grupos sociais, ou seja, os setores sociais subalternos. Além das reivindicações locais, nacionais e regionais, cabe reconhecer que há reivindicações que são comuns a amplos setores sociais das diferentes sociedades nacionais, da Sociedade civil mundial em formação. Nesse novo mapa da história, nesse novo palco de lutas sociais denominado "mundialização", "transnacionalização", "globalização", ou mesmo "planetarização", abrem-se espaços para um novo e difícil "internacionalismo" ou, mais propriamente, uma globalização desde baixo, na qual estão engajados indivíduos e coletividades, classes sociais e grupos sociais, partidos políticos e sindicatos, movimentos sociais e correntes de opinião pública, expressando outras e novas formas de hegemonia.

Este é o dilema: trata-se de globalizar as organizações, reivindicações e formas de lutas dos setores sociais subalternos. Diante da crescente globalização das organizações e decisões dos setores sociais dominantes, dos blocos de poder político-econômico predominantes em escala mundial, não resta aos setores subalternos senão se organizarem, desenvolvendo novas formas de inteligência do que são as relações, os processos e as estruturas que se criam com a globalização; podendo assim formular outras e novas formas de reivindicação e luta em escala mundial. Todas as reivindicações locais, nacionais e regionais, que continuam fundamentais para indivíduos e coletividades, têm sempre alguma ou muita implicação global. As fábricas, os escritórios, os meios de comunicação, os centros decisórios, tudo o que diz respeito ao globalismo está disperso em diferentes países, continentes, ilhas e arquipélagos dispersos no novo mapa do mundo; disperso, mas altamente organizado, em geral altamente organizado e centralizado em cidades globais. Sendo assim, o adequado conhecimento dos processos e das estruturas que constituem e movem o capitalismo global pode ser um primeiro momento da consciência crítica sobre o que e como fazer para bloquear e eventualmente desmontar o tipo de globalização que sataniza a maior parte da humanidade.

Octavio Ianni, sociólogo e professor emérito da Universidade de São Paulo, é professor do Departamento de Sociologia do Instituto de Filosofia e Ciências Humanas da Unicamp. É autor, entre outras obras, de $A$ idéia de Brasil moderno (Brasiliense), O labirinto latinoamericano (Vozes), Teorias da globalização (Civilização Brasileira) e Enigmas da modernidade-mundo (Civilização Brasileira, no prelo). 